\title{
ANALISIS PERAN FUNCTIONAL BENEFITS, SYMBOLIC BENEFITS, EXPERIENTIAL BENEFITS DAN CUSTOMER SATISFACTION SEBAGAI PEMBENTUK LOYALTY INTENTION PADA CUSTOMER THE BODY SHOP (TELAAH PADA: THE BODY SHOP DI WILAYAH JAKARTA)
}

\author{
Santi Rimadias \\ Farah Safira Rachmayanti
}

\begin{abstract}
The purpose of this research was conducted to identify the effect of functional benefits, symbolic benefits, experiential benefits and customer satisfaction towards loyalty intention from the customer who use The Body Shop.

With a high market demand on cosmetics nowadays, producers are required to compete to meet costumer's expectations. This research was a quantitative descriptive research. There were 153 respondents which were gathered by convenience sampling.

The results showed that functional benefits, symbolic benefits and experiential benefits had a positive and significant affect toward customer satisfaction. Furthermore, this research also showed that customer satisfaction had a positive and significant effect on loyalty intention.
\end{abstract}

Keywords: loyalty intention, customer satisfaction, symbolic benefits, functional benefits, experiential benefits.

\section{PENDAHULUAN}

\subsection{Latar Belakang Masalah}

Globalisasi memberikan dampak besar kepada perkembangan bisnis termasuk di Indonesia itu sendiri. Hal tersebut menjadikan semakin beragamnya pasar maupun peluang di pasar, yang mengakibatkan semakin ketatnya persaingan (Mulyadi, 2015). Pada kondisi ini, perusahaan dituntut agar dapat menciptakan keunggulan dari produk maupun jasa yang ditawarkannya sehingga produk maupun jasa yang ditawarkan perusahaan mampu bersaing di pasar.

Menurut data yang diambil dari Departemen Perdagangan AS, melalui Biro Sensusnya, Indonesia dengan jumlah penduduk terbesar nomor empat di dunia, yaitu sebesar 253,60 juta jiwa (Purnomo, 2014) dan dengan angka tersebut akan menambah potensi jumlah pelanggan suatu perusahaan menjadi lebih tinggi, ditambah Indonesia merupakan sebuah Negara yang tingkat konsumtif dari penduduknya itu sendiri cukup tinggi. Akan tetapi hal tersebut tidak menjadikan para pelaku bisnis di Indonesia dengan mudah mendapatkan pelanggan, sehingga penting bagi perusahaan menimbulkan minat pelanggan untuk loyal (loyalty intention) terhadap brand perusahaan.

Russell-Bennett \& Rundle-Thiele (2004) mengatakan bahwa, pada umumnya, pelanggan yang puas lebih mungkin untuk menunjukkan perilaku loyal, yaitu pembelian ulang dan kesediaan untuk memberikan kata positif dari mulut ke mulut (Sondoh Jr., Omar, Wahid, Ismail, \& Amran, 2007). Karena saat seorang pelanggan mendapatkan kepuasan terhadap suatu produk maka besar kemungkinan pelanggan tersebut dapat berkeinginan 
Analisis Peran ...

untuk tetap loyal (loyalty intention) pada produk tersebut. Membahas mengenai loyalty intention atau keinginan untuk loyal akan suatu produk, berbeda dengan loyalty yang artinya pelanggan sudah loyal terhadap produk tersebut, ialah pelangan yang baru membeli produk suatu brand kemudian berkeinginan untuk loyal menggunakan produk brand tersebut. Banyak faktor yang dapat memunculkan keinginan tersebut salah satunya kepuasan keseluruhan yang dirasakan serta manfaat dari image yang kuat akan produk brand tersebut.

Russell-Bennett \& Rundle-Thiele (2004) mengatakan bahwa kepuasan pelanggan sepenuhnya dianggap sebagai isu penting bagi setiap manajer pemasaran. Hal tersebut biasanya digunakan sebagai patokan kinerja pemasaran dari sebuah perusahaan (Sondoh Jr. et al., 2007). Kepuasan secara keseluruhan akan suatu produk kini tidak hanya berdasarkan dari kegunaan produk tersebut saja tetapi juga dapat berasal dari value lebih yang dihasilkan. Value lebih yang dihasilkan produk disini maksudnya adalah bagaimana sebuah produk dapat mendongkrak rasa percaya diri dan citra diri dari manfaat yang dihasilkan produk sehingga pelanggan merasa puas setelah mengonsumsinya yang kemudian akan memberikan kepercayaan kepada pelanggan untuk tetap ingin menggunakan produk tersebut dikemudian hari.

Brand image suatu produk bahkan dapat merefleksikan atau menggantikan makna asli dari produk tersebut. Seperti contoh brand Aqua yang merefleksikan air mineral atau brand Pepsodent merefleksikan pasta gigi dan beberapa produk lainnya. Pada zaman ini citra atau image yang kuat dari sebuah produk dapat menghasilkan benefits value yang lebih dari produk itu sendiri. Brand image benefits memiliki tiga dimensi (Keller, 1993). Dimensi tersebut diantaranya functional benefits, symbolic benefits, dan experiential benefits. Oleh karena itu, brand image pada zaman ini mempunyai peran penting dalam memberikan value tambahan terhadap suatu produk. Sehingga dapat meningkatkan satisfaction (Baharun, Hashim, \& Sulong, 2013).

Dewasa ini banyak disuarakan mengenai global warming atau go green, banyak masyarakat yang telah menyadari pentingnya menjaga lingkungan, dampak buruk polusi, efek negatif dari produk-produk kimiawi dan hal lainnya. Selain berdampak buruk pada lingkungan juga dapat berdampak terhadap tubuh manusia itu sendiri. Para pelaku usaha juga menyadari hal ini dan untuk memenuhi keinginan masyarakat akan produk-produk yang bersifat alami dan mendukung gerakan go green, banyak dari mereka mulai menemukan inovasi mengenai produk-produk berbahan dasar alami dan mendukung gerakan go green, salah satunya ialah The Body Shop.

Untuk memenuhi keinginan masyarakat akan produk yang kosmetik alami, The Body Shop menghadirkan inovasi yang baru di pasar Indonesia yaitu brand yang memproduksi produk kosmetik berbahan alami dan ramah lingkungan. The Body Shop juga menanamkan image dimasyarakat sebagai merek dengan produk 100\% berbahan alami dan mendukung gerakan go green. Kecantikan jauh lebih dari sekedar wajah cantik. The Body Shop percaya bahwa kecantikan sejati berasal dari kepercayaan diri, vitalitas dan pikiran positif manusia (The Body Shop, 2015).

Sehingga pada penelitian ini objek yang digunakan ialah merek The Body Shop untuk melihat apakah brand image benefits yang ditanamkan serta kepuasan pelanggan (customer satisfaction) mampu berperan penting terhadap minat untuk loyal (loyalty 
intention) pada merek ini. Peran customer satisfaction dan loyalty intention merupakan faktor penting dalam peningkatan penjualan secara berkelanjutan sehingga dapat menjadikan merek The Body Shop mampu bersaing dengan merek lainya baik yang berbahan alami maupun kimiawi.

Saat seseorang telah merasa bahwa produk yang dipakai mempunyai brand image benefits baik maka keinginan untuk loyal terhadap produk tersebut akan semakin tinggi, serta apabila seseorang merasa brand image benefits akan suatu produk tinggi maka terdapat kepuasan tersendiri yang dirasakan dan kepuasan itu akan mendukung semakin kuatnya keinginan untuk loyal terhadap merek tersebut. Sehingga, penulis berniat melakukan penelitian yang berjudul 'Analisis Peran Functional Benefits, Symbolic Benefits, Experiential Benefits Dan Customer Satisfaction sebagai pembentuk Loyalty Intention pada Customer The Body Shop'

\section{LANDASAN TEORI}

\subsection{Functional Benefits}

Functional benefits terkait dengan keuntungan intrinsik produk atau jasa yang dikonsumsi dan biasanya sesuai dengan atribut produk terkait. Maslow (1970) menyebutkan manfaat ini sering dihubungkan dengan motivasi cukup mendasar, seperti kebutuhan fisiologis dan keamanan, dan Fennell (1978); Rossiter dan Percy (1987) melibatkan keinginan untuk menghilangkan atau menghindari masalah (Keller, 1993). Atribut yang dimaksud disini misalnya, warna, penampilan atau bentuknya, kenyamanan, fitur, harga dan kehandalannya (Sweeney \& Soutar, 2001).

Pada penelitian Baharun et al. (2013) functional benefits itu sendiri umumnya sesuai dengan atribut yang terkait dengan produk seperti keuntungan finansial, keamanan, perencanaan dan nilai tambah suatu pelayanan. Apabila disesuaikan dengan The Body Shop, maka functional benefits disini umumnya sebagai keuntungan yang diterima dari kegunaan produk merek The Body shop maupun hasil dari kegunaan produk merek The Body Shop.

\subsection{Symbolic Benefits}

Menurut (Chen \& Chen, 2014) biasanya symbolic benefits dirancang untuk menghubungkan individu dengan populasi tertentu, peran atau citra diri, dengan kata lain, brand image produk yang dapat memenuhi kebutuhan internal pelanggan untuk meningkatkan harga diri mereka, reputasi sosial, fitur produk serta karakteristik pelayan disetiap store.

Symbolic benefits dikaitkan dengan kebutuhan mengenai penerimaan kelas sosial atau ekspresi diri dan pada dasarnya berhubungan dengan atribut non-produk. Solomon (1983) menambahkan bahwa konsumen akan menillai sebuah pamor, keeksklusifan, atau kemampuan fashion sebuah brand dari seberapa berkaitannya brand dengan konsep diri mereka (Keller, 1993). Menurut Koh, Yoo dan Boger Jr (2010) symbolic benefits juga dikaitkan dengan kebutuhan akan pendekatan sosial atau ekspresi dari diri seseorang (Baharun et al., 2013). 
Analisis Peran ...

\subsection{Experiential Benefits}

Experiential benefits adalah sesuatu yang dirasakan pelanggan setelah memakai produk atau jasa dan biasanya berhubungan dengan atribut produk tersebut (Sondoh Jr. et al., 2007). Manfaat ini memuaskan kebutuhan experiential seperti kesenagan indera, variasi, dan stimulasi kognitif (Keller, 1993). Experiential benefits juga dianggap sebagai pendukung untuk meningkatkan intesitas penggunaan produk (Keller, 2013). Seberapa puas pelanggan menggunakan produk atau jasa yang dikonsumsinya (Baharun et al., 2013).

\subsection{Customer Satisfaction}

Menurut Bitner \& Hubbert (1994) customer satisfaction adalah penilaian evaluatif pada pembelian yang dilakukan terakhir kali berdasarkan semua pelayanan yang telah diterima (Nam, Ekinci, \& Whyatt, 2011). Dengan demikian customer satisfaction merupakan merupakan hasil dari semua transaksi terhadap kepuasan tertentu dengan pelayanan baik yang dihadapkan (Veloutsou, Gilbert, Moutinho, \& Goode, 2005). Oliver (1997) mendefinisikan kepuasan sebagai respon pemenuhan konsumen. Hal tersebut merupakan penilaian atas fitur produk atau jasa, ataupun nilai dari produk atau jasa itu sendiri, maupun yang disediakan atau menyediakan dan tingkat kesenangan dari pemenuhan konsumsi yaitu dibawah atau melebihi tingkat pemenuhan kebutuhan. Secara keseluruhan kepuasan merupakan penilaian evaluatif pembelian terakhir kesempatan dan berdasarkan semua pertemuan dengan penyedia layanan (Bitner, Faranda, Hubbert, \& Zeithaml, 1997).

Auh, Salisbury, \& Johnson (2003) mengemukakan kepuasan dalam bertransaksi mungkin bervariasi dari pengalaman konsumen, untuk mengalami kepuasan secara keseluruhan dengan cara bergerak dalam rata-rata yang relatif stabil dan paling mirip dengan sikap keseluruhan terhadap pembelian merek (Nam et al., 2011). Konsep ini penting karena kepuasan secara keseluruhan mempengaruhi indikator loyalitas dalam jangka waktu ke depan pada kinerja bisnis (Fornell, Johnson, \& Anderson, 1996).

Pada penelitian sebelumnya, kepuasan konsumen difokuskan terutama pada efek harapan, disconfirmation harapan, kinerja, mempengaruhi, dan ekuitas pada kepuasan (Szymanski \& Henard, 2001). Pentingnya harapan telah diakui dalam studi sebelumnya pada kepuasan pelanggan (Churcill Jr \& Surprenant, 1982; Oliver, 1980; Tse \& Wilton, 1988). Harapan pelanggan adalah keyakinan pra-sidang tentang produk (Olson \& Dover, 1979) yang berfungsi sebagai standar pembanding atau titik referensi terhadap kinerja produk tersebut dinilai (Bearden \& Teel, 1983; Oliver, 1980). Paradigma diskonfirmasi harapan menunjukkan bahwa konsumen merasa puas ketika produk berperforma lebih baik dari yang diharapkan (positive disconfirmation), tidak puas ketika harapan konsumen melebihi kinerja negatif produk (negative disconfirmation), dan merupakan kepuasan netral ketika harapan seimbang dengan kinerja produk (nol disconfirmation) (Bearden \& Teel, 1983; Churcill Jr \& Surprenant, 1982; Oliver \& DeSarbo, 1988; Oliver, 1980).

Beberapa peneliti telah meneliti berbagai jenis standar perbandingan alternatif di samping harapan seperti norma berbasis pengalaman (Cadotte, Woodruff, \& Jenkins, 1987; Woodruff, Cadotte, \& Jenkins, 1983); Teori ekuitas (Oliver \& Swan, 1989; Tse \& Wilton, 1988); keinginan (Spreng \& Olshavsky, 1993), dan kinerja yang ideal (Tse \& Wilton, 1988). 
Semua itu merupakan standar perbandingan yang telah diuji secara empiris dalam penelitian kepuasan ataupun ketidakpuasan pelanggan.

Selain dari standar komparatif faktor kepuasan, peneliti lainnya telah mengeksplorasi dengan beberapa prediktor potensi kepuasan seperti kualitas produk atau layanan (Bei \& Chiao, 2001; Chiou, Droge, \& Hanvanich, 2002; Sivadas \& Baker- Prewitt, 2000); nilai yang dirasakan (Yang \& Peterson, 2004); layanan perhotelan pengalaman desain (Pullman \& Gross, 2004); hubungan manfaat konsumen (K. E. Reynolds \& Beatty, 1999); dan retail atau image toko (Bloemer \& Ruyter, 1998; Koo, 2003).

\subsection{Loyalty Intention}

Niat untuk membeli kembali dapat diukur dengan menayakan kepada konsumen tentang niat mereka dimasa yang akan datang untuk membeli kembali produk atau jasa tertentu (Jones \& Sasser, 1995). Jacoby \& Chestnut (1978) telah mengidentifikasi bahwa lebih dari 50 definisi operasional loyalitas merek, yang dapat diklasifikasikan sebagai perilaku, sikap dan pendekatan komposit dalam literaturnya (Sondoh Jr. et al., 2007).

Kemudian Brown (1952) menganggap bahwa perilaku loyal sebagai frekuensi pembelian ulang atau menurut Cunningham (1956) sebagai proporsi dari pembelian (Sondoh Jr. et al., 2007), pada Mellens, Dekimpe, \& Steenkamp (1996) mengemukakan bahwa sikap loyalitas merek terdiri dari menyatakan preferensi, niat berkomitmen atau niat membeli seorang pelanggan (Sondoh Jr. et al., 2007). Namun, sebagian besar definisi perilaku di atas dikritik oleh Oliver (1999), Jacoby \& Chestnut (1978) dan Day (1969) karena dinilai bermasalah (Sondoh Jr. et al., 2007). Jacoby \& Chestnut (1978) serta Oliver (1997) mengusulkan bahwa definisi komposisi loyalitas menekankan dua pendekatan yang berbeda, pertama loyalitas merupakan perilaku dan yang kedua loyalitas merupakan konsep sikap (Sondoh Jr. et al., 2007).

Jacoby \& Chestnut (1978) memberikan definisi konseptual loyalitas merek sebagai proses terhadap pemilihan satu merek atau lebih dari beberapa merek dan fungsi psikologis yang ada sebagai evaluasi yang kemudian menjadi pengambilan keputusan untuk loyal (Sondoh Jr. et al., 2007). Oliver (1997) mendefinisikan loyalitas pelanggan sebagai komitmen yang mendalam untuk membeli kembali atau berlangganan kembali atas produk atau jasa yang disukai secara konsisten di masa depan, sehingga menyebabkan berulangnya pembelian merek yang sama atau perlengkapan merek yang sama, meskipun pengaruh situasi dan kegiatan pemasaran memiliki potensi beralihnya suatu perilaku (Sondoh Jr. et al., 2007).

Selain itu, beberapa akademisi menyarankan agar menggunakan pendekatan gabungan yaitu pendekatan sikap dan perilaku karena akan memperkuat definisi loyalitas merek (Day, 1969). Kemudian perusahaan disarankan agar mampu, pertama dapat menangkap informasi mengenai niat pembelian kembali ketika mengukur kepuasan, sehingga memudahkan perusahaan untuk menghubungkan niat dan kepuasan demi tujuan analisis, kedua dapat menjalin hubungan dengan pelanggan sehingga memiliki hubungan yang baik demi kegiatan pembelian kembali dan dalam siklus yang panjang, dan ketiga harus bisa melihat minat untuk pembelian kembali itu sendiri (Jones \& Sasser, 1995).

Masalah utama loyalitas yaitu tentang bagaimana loyalitas dioperasionalkan. Hal ini sangat penting untuk memahami bagaimana mengukur loyalitas. Meskipun ada tiga 
Analisis Peran ...

pendekatan yang dapat digunakan untuk mengukur loyalitas yaitu pendekatan perilaku, pendekatan sikap, dan pendekatan gabungan keduanya, sebagian besar peneliti menggunakan pendekatan sikap pada loyalty intention dan niat untuk merekomendasikan sebagai indikator loyalitas (Chiou et al., 2002; Kandampully \& Suhartanto, 2000; Lau \& Lee, 1999; Sivadas \& Baker- Prewitt, 2000).

\subsection{Rerangka Konseptual}

\subsubsection{Semakin tinggi functional benefits yang dirasakan menyebabkan semakin tinggi tingkat kepuasan pelanggan}

Menurut Berry dan Parasuraman (1991); Berry (1995) menyatakan bahwa atribut yang mendatangkan manfaat yang dibutuhkan oleh pelanggan lebih menyebabkan kepuasan pelanggan (W.-H. Wang, Liang, \& Joonas, 2009).

Adanya pengaruh positif antara functional benefits dan customer satisfaction disebabkan ketika seorang konsumen memperoleh keuntungan dari fungsi suatu produk yang dibelinya maka akan timbul perasaan puas akan produk tersebut, kerena salah satu tujuan pembelian suatu produk ialah agar mendapatkan keuntungan dari fungsi produk tersebut. Bahkan berlaku sebaliknya bahwa saat suatu produk tidak dapat berfungsi secara maksimal sesuai yang diharapkan maka rasa kepuasaan konsumen terhadap produk tersebut pun akan menghilang. Sehingga penulis disini beranggapan bahwa terdapat hubungan positif diantara keduanya.

H1: Semakin tinggi functional benefits yang dirasakan menyebabkan semakin tinggi tingkat kepuasan pelanggan.

\subsubsection{Semakin tinggi symbolic benefits yang dirasakan menyebabkan semakin tinggi tingkat kepuasan pelanggan}

Sesuai penelitian oleh W.-H. Wang et al., (2009) ditemukan hasil bahwa symbolic benefits dan experiential benefits merupakan sumber utama penghasil kepuasaan pelanggan. Pada penelitian Neupane (2015) ditunjukkan bahwa koefisien kolerasi symbolic benefits dan kepuasan pelanggan secara keseluruhan menunjukkan hasil positif dan sangat signifikan.

Dewasa ini terdapat hal lain dari sekedar functional dan experiential benefits yang diharapkan seorang konsumen ketika membeli suatu produk, yaitu symbolic benefits. Symbolic benefits bisa diartikan sebagai gambaran yang merepresentasikan diri konsumen terhadap gaya hidup sosialnya. Sehingga saat seseorang merasa bangga dan tergambarkan dirinya atas merek tersebut maka pelanggan akan timbul perasaan puas. Sehingga penulis beranggapan bahwa terdapat hubungan positif antara keduanya.

H2: Semakin tinggi symbolic benefits yang dirasakan menyebabkan semakin tinggi tingkat kepuasan pelanggan.

\subsubsection{Semakin tinggi experiential benefits yang dirasakan menyebabkan semakin tinggi tingkat kepuasan pelanggan}

Menurut penelitian yang telah dilakukan oleh W.-H. Wang et al., (2009) menunjukkan hasil symbolic benefits dan experiential benefits adalah sumber utama yang mendatangkan kepuasan pelanggan.

Experiential benefits dapat digambarkan sebagai sensasi yang dihasilkan atas penggunaan produk tersebut. Penulis beranggapan bahwa terdapat hubungan positif 
diantara experiential benefits dan customer satisfaction dikarenakan saat seorang konsumen membeli suatu produk dan setelah itu merasa nyaman serta senang atas penggunaan produk tersebut saat memakainya maka hasil akhir yang dirasakan konsumen ialah kepuasaan karena menggunakan atau mengonsumsi produk tersebut. Berlaku sebaliknya, jika konsumen tidak mendapatkan experiential benefits yang diharapkan maka tingkat kepuasan yang konsumen dapatkan pun akan hilang.

H3: Semakin tinggi experiential benefits yang dirasakan menyebabkan semakin tinggi tingkat kepuasan pelanggan.

\subsubsection{Adanya pengaruh positif antara customer satisfaction dan loyalty intention}

Ketika konsumen merasa puas dengan suatu produk atau merek, mereka lebih cenderung untuk merekomendasikan produk kepada orang lain, tidak cenderung beralih ke merek alternatif lain, dan cenderung untuk mengulang pembelian (Bennett \& Rundle-Thiele, 2004). Pelanggan yang tidak puas lebih mungkin mencari informasi tentang alternatif lain sehingga cenderung menerima tawaran dari pesaing dibandingkan pelanggan yang puas (Anderson \& Srinivasan, 2003). Selain itu, penelitian dari Y. Wang, Tang, \& Tang (2001) menunjukkan bahwa kepuasan merupakan alat ukur yang reliabel untuk niat pembelian kembali.

Adanya hubungan positif antara kepuasan pelanggan dan keinginan untuk loyal dimana konsumen mencapai tingkat kepuasan yang tinggi sehingga menimbulkan keinginan kuat untuk berkomitmen jangka panjang dengan merek perusahaan.

H4: Adanya pengaruh positif antara customer satisfaction dan loyalty intention.

\subsection{Model Penelitian}

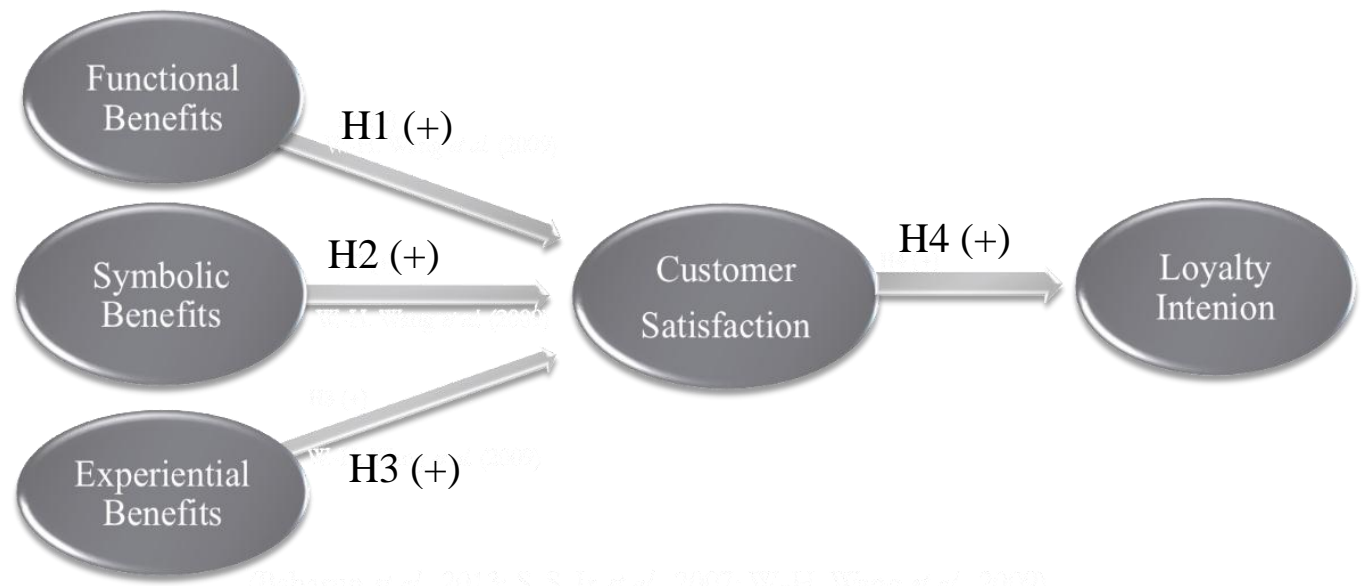

Sumber: (Baharun et al., 2013; Sondoh Jr. et al., 2007; W.-H. Wang et al., 2009)

Model penelitian ini dimodifikasi dari penelitian terdahulu yang dilakukan oleh Baharun et al. (2013) dengan judul "Benefit Segmentation for Unit trust Products in Malaysian Financial service Industry”, Sondoh Jr. et al. (2007) dengan judul “The Effect of Brand Image On Overall Satisfaction And Loyalty Intention In The Context of Color Cosmetic" dan W.-H. Wang et al. (2009) dengan judul "Customer Relationship Investments, Value to the Customer, and Value to the Firm: Integrating Attributes and Benefits". 
Analisis Peran ...

\section{METODOLOGI PENELITIAN}

\subsection{Objek Penelitian}

Perusahaan yang akan dibahas dalam penelitian ini adalah perusahaan kosmetika The Body Shop. The Body Shop International plc, atau lebih dikenal dengan The Body Shop, memiliki sekitar 2,400 toko di 61 negara. The Body Shop menekankan dukungannya terhadap berbagai macam isu yang beredar di seluruh dunia. Slogan-slogan mereka antara lain adalah: Against Animal Testing (Lawan Uji Coba terhadap Hewan), Support Community Trade, Activate Self Esteem, Defend Human Rights (Tegakkan HAM), dan Protect Our Planet (Proteksikan Planet Kita) (The Body Shop, 2015).

Secara singkat, The Body Shop perusahaan franchise berbasis di Inggris, operasionalnya di Indonesia dibawah naungan PT Monica Hijau Lestari. Toko pertama The Body Shop Indonesia dibuka Tahun 1992 di Pondok Indah Mall, Jakarta. Sasaran responden penelitian ini adalah konsumen yang pernah melakukan pembelian produk merek The Body Shop khususnya di Jakarta karena telah memiliki 35 stores (http://www.streetdirectory.co.id/businessfinder/indonesia/jakarta/company branch/7419/7 493/, diakses 17 Maret 2015) dari 100 stores yang ada di Indonesia (https://id.linkedin.com/company/pt.monica-hijau-lestari-the-body-shop-indonesia-, diakses 17 Maret 2015). Selain itu pada tahun 2014, The Body Shop termasuk ke dalam Top 50 Cosmetic Brand, peringkatnya naik ke posisi 23 dari posisi 35 Tahun 2013 (http://brandirectory.com/league tables/table/cosmetics-50-2014, diakses 17 Maret 2015).

\subsection{Desain Penelitian}

Penelitian ini merupakan penelitian descriptive. Yaitu, jenis penelitian yang memiliki tujuan utama mendeskripsikan sesuatu biasanya karakteristik atau fungsi pasar (Malhotra, 2010). Dalam penelitian ini, peneliti menggunakan metode penelitian kuantitatif yang dilakukan satu kali dalam satu periode (cross sectional design). Metode penelitian kuantitatif sendiri bertujuan untuk mengukur data dan biasanya ada dalam bentuk analisis statistik (Malhotra, 2010). Pengumpulan data dalam penelitian ini dilakukan dengan metode survey, caranya menyebarkan kuisioner kepada konsumen yang pernah bertransaksi di store The Body Shop tersebut dalam bentuk pertanyaan. Hasil dari data kuisioner kemudian diolah dengan menggunakan metode analisis regresi. Dalam penelitian ini dibahas mengenai penelitian yang menghubungkan peran functional benefits, symbolic benefits, experiential benefits dan customer satisfaction sebagai pembentuk loyalty intention pada customer The Body Shop.

\subsection{Metode Penghimpunan Data}

Metode pengambilan sampel dalam penelitian ini adalah non-probability sampling dengan teknik convenience sampling. Non-probability sampling merupakan teknik pengambilan sampel yang tidak menggunakan pemilihan peluang dan tergantung pada keputusan personal peneliti, sedangkan convenience sampling berarti sampel penelitian dipilih berdasarkan penilaian peneliti, yaitu masyarkat yang membeli dan menggunakan produk merek The Body Shop di Jakarta (Malhotra, 2010). 


\subsection{Operasionalisasi Variabel}

Tabel 3.1 Operasionalisasi Variabel

\begin{tabular}{|c|c|c|c|}
\hline Variabel & Definisi & Indikator & $\begin{array}{c}\text { Skala } \\
\text { Pengukuran }\end{array}$ \\
\hline $\begin{array}{c}\text { Functional } \\
\text { benefits }\end{array}$ & $\begin{array}{l}\text { Hubungan secara } \\
\text { intrinsik dengan } \\
\text { keuntungan dari } \\
\text { konsumsi sebuah } \\
\text { produk atau jasa } \\
\text { yang memiliki } \\
\text { hubungan dengan } \\
\text { atribut produk } \\
\text { (Sondoh Jr. et al., } \\
\text { 2007) }\end{array}$ & $\begin{array}{l}\text { (a) Merek The Body Shop } \\
\text { menunjukkan hasil sesuai dengan } \\
\text { kegunaannya. (FU1) } \\
\text { (b) Merek The Body Shop membuat } \\
\text { Saya terlihat menarik. (FU2) } \\
\text { (c) Merek The Body Shop dapat } \\
\text { diandalkan dalam penggunaan. } \\
\text { (FU3) (Sondoh Jr. et al., 2007) }\end{array}$ & Interval \\
\hline $\begin{array}{l}\text { Symbolic } \\
\text { benefits }\end{array}$ & $\begin{array}{c}\text { Kebutuhan } \\
\text { mengenai } \\
\text { penerimaan kelas } \\
\text { sosial atau } \\
\text { ekspresi diri. } \\
\text { (Keller, 1993) }\end{array}$ & \begin{tabular}{|l|} 
(a) Merek The Body Shop \\
memberikan pandangan bahwa \\
Saya memiliki gaya hidup yang \\
Saya inginkan. (SY1) \\
(b) Merek The Body Shop \\
membantu Saya untuk lebih \\
masuk ke dalam kelompok sosial \\
Saya. (SY2) \\
(c) Merek The Body Shop \\
meningkatkan cara Saya dianggap \\
oleh orang lain. (SY3) (Sondoh Jr. \\
et al., 2007)
\end{tabular} & 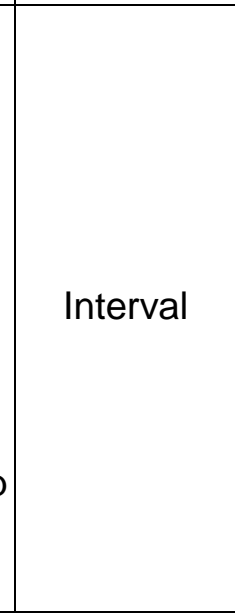 \\
\hline $\begin{array}{c}\text { Experiential } \\
\text { benefits }\end{array}$ & $\begin{array}{c}\text { Apa yang } \\
\text { dirasakan } \\
\text { pelanggan setelah } \\
\text { memakai produk } \\
\text { atau jasa dan } \\
\text { berhubungan } \\
\text { pada atribut } \\
\text { produk tersebut } \\
\text { (Sondoh Jr. et al., } \\
\text { 2007) }\end{array}$ & $\begin{array}{l}\text { (a) Merek The Body Shop } \\
\text { meningkatkan frekuensi } \\
\text { penggunaan Saya. (EX1) } \\
\text { (b) Saya mendapatkan kesenangan } \\
\text { dari menggunakan Merek The } \\
\text { Body Shop. (EX2) } \\
\text { (c) Saya nyaman menggunakan } \\
\text { merek The Body Shop. EX3) } \\
\text { (Sondoh Jr. et al., 2007) }\end{array}$ & Interval \\
\hline
\end{tabular}




\begin{tabular}{|c|c|c|c|}
\hline Variabel & Definisi & Indikator & Skala \\
\hline $\begin{array}{l}\text { Customer } \\
\text { satisfaction }\end{array}$ & $\begin{array}{c}\text { Bitner \& Hubbert } \\
\text { (1994) } \\
\text { mendefiniskan } \\
\text { sebagai penilaian } \\
\text { evaluatif pada } \\
\text { pembelian yang } \\
\text { dilakukan terakhir } \\
\text { kali berdasarkan } \\
\text { semua pelayanan } \\
\text { yang telah diterima } \\
\text { (Nam et al., 2011) }\end{array}$ & $\begin{array}{l}\text { (a) Merek The Body Shop } \\
\text { memenuhi kebutuhan Saya } \\
\text { dengan baik. (SAT1) } \\
\text { (b) Saya sangat puas } \\
\text { menggunakan merek The } \\
\text { Body Shop. (SAT2) } \\
\text { (c) Keputusan Saya } \\
\text { menggunakan merek The } \\
\text { Body Shop merupakan } \\
\text { keputusan yang tepat. } \\
\text { (SAT3) } \\
\text { (Sondoh Jr. et al., 2007) } \\
\text { (d) Merek The Body Shop } \\
\text { adalah salah satu merek } \\
\text { terbaik yang pernah Saya } \\
\text { pilih. (SAT4) (Sweeney \& } \\
\text { Soutar, 2001) }\end{array}$ & Interval \\
\hline $\begin{array}{l}\text { Loyalty } \\
\text { intention }\end{array}$ & $\begin{array}{l}\text { Keinginan } \\
\text { pembelian ulang } \\
\text { dan kesediaan } \\
\text { untuk } \\
\text { memberikan word } \\
\text { of mouth yang } \\
\text { positif } \\
\text { (Sondoh Jr. et al., } \\
\text { 2007) }\end{array}$ & $\begin{array}{l}\text { (a) Merek The Body Shop } \\
\text { adalah pilihan pertama } \\
\text { Saya. (LOY1) } \\
\text { (b) Saya berniat untuk terus } \\
\text { menggunakan merek The } \\
\text { Body Shop. (LOY2) } \\
\text { (c) Saya lebih cenderung } \\
\text { untuk membeli kembali } \\
\text { merek The Body Shop. } \\
\text { (LOY3) } \\
\text { (d) Saya akan } \\
\text { menganjurkan teman dan } \\
\text { kerabat Saya untuk } \\
\text { menggunakan merek The } \\
\text { Body Shop. (LOY4) } \\
\text { (Sondoh Jr. et al., 2007) } \\
\text { (e) Saya membahas merek } \\
\text { The Body Shop kepada } \\
\text { orang lain. (LOY5) } \\
\text { (Johnson, Herrmann, \& } \\
\text { Huber, 2006) }\end{array}$ & Interval \\
\hline
\end{tabular}




\section{ANALISIS DAN PEMBAHASAN}

\subsection{Profil Responden}

Responden berjumlah 153 orang, dapat ditunjukkan responden wanita lebih besar dari pada jumlah responden pria, yaitu pria berjumlah 50 orang dan wanita berjumlah 103 orang. Dari 153 responden, mayoritas responden dalam penelitian ini berusia antara 18 hingga 27 tahun dengan jumlah 108 orang, kemudian diikuti yang berusia $28-37$ tahun dengan jumlah 23 orang, sisanya sebanyak 14 orang berusia $38-47$ tahun dan 8 orang untuk usia $>47$ tahun. Untuk pendidikan terakhir dari 153 responden adalah SMA / SMK / Sederajat dengan jumlah 79 orang, kemudian berpendidikan Strata 1 (S1) berjumlah 57 orang, dibawahnya berpendidikan Diploma (D3) berjumlah 11 orang, peringkat ke-4 terbanyak berpendidikan Pasca Sarjana (S2), sisanya 3 orang berpendidikan terakhir SD / SMP dan 1 orang berpendidikan S3. Pekerjaan dari 153 responden, jumlah terbesar berstatus pelajar atau mahasiswa dengan total 70 orang, lalu yang berstatus sebagai karyawan sebanyak 40 orang, kemudian yang berstatus ibu rumah tangga sebanyak 17 orang, 13 orang dari businessman / businesswoman, wiraswasta sebanyak 8 orang dan 5 orang PNS.

Domisili dari 153 responden antara lain di wilayah Jakarta Selatan sebanyak 87 orang, diikuti yang berdomisili di Jakarta Timur sebesar 37 orang, kemudian 15 orang berdomisili di Jakarta Pusat, sisanya 8 orang berada di wilayah Jakarta Utara dan 6 orang berada di Jakarta Barat.

\subsection{Hasil Analisis Data}

Hasil validitas dan reliabilitas menunjukkan bahwa seluruh variabel memenuhi kriteria yang ditentukan (Factor Loading $\geq 0,70$; Construct Realibility $\geq 0,70$; Variance Extracted $\geq$ 0,50 .

Tabel 4.1 Output Regression Weights

\begin{tabular}{|c|c|c|c|c|}
\hline Hipotesis & Path & Estimasi & $\mathbf{P}$ & Kesimpulan \\
\hline 1 & SAT <--- FU & 0.221 & ${ }^{* *}$ & Didukung Data \\
\hline 2 & SAT <--- SY & 0.364 & ${ }^{* * *}$ & Didukung Data \\
\hline 3 & SAT <--- EX & 0.640 & ${ }^{* *}$ & Didukung Data \\
\hline 4 & LOY <--- SAT & 1.106 & ${ }^{* * *}$ & Didukung Data \\
\hline
\end{tabular}

Hasil pengolahan data output regression weights yang menunjukkan apakah hipotesis yang diajukan didukung data atau tidak dengan syarat nilai $p$-value $\geq 0,05$. Semua variabel memenuhi syarat nilai yang diinginkan sehingga seluruh data mendukung hipotesis.

\subsection{Implikasi Manajerial}

Berdasarkan hasil penelitian dapat diberikan implikasi manajerial untuk pihak The Body Shop selaku pihak yang menyediakan produk kosmetik berbahan dasar alami. Beberapa implikasi yang dapa diberikan kepada pihak manajemen The Body Shop adalah sebagai berikut.

1. Persaingan perdagangan didunia kosmetik cukup ketat, dewasa ini pelanggan juga semakin mementingkan keuntungan yang dirasakan selain hanya membeli produk dari merek yang dipilihnya. Pertama pelanggan melihat dari segi functional benefits yang 
Analisis Peran ...

dirasakan pelanggan sesuai dengan yang diharapkan dari fungsi yang ada dari produk pilihan pelanggan. functional benefits yang diberikan merek The Body Shop tentunya harus dipertahankan serta ditingkatkan agar hasil yang dirasakan pelanggan dapat terus berjalan maksimal. Manfaat fungsi yang dirasakan merupakan hal pertama yang pelanggan pertimbakan dalam membeli produk. Sehingga jika manfaat fungsinya sesuai dengan yang seharusnya, maka pelanggan tertarik untuk menggunakan produk yang kemudian akan dipilihnya.

Mempertahankan pelanggan agar dapat tetap merasakan functional benefits yaitu dengan tetap memberikan pelayanan penjelasan kepada pelanggan yang datang ke store The Body Shop mengenai fungsi dari produk yang dibutuhkan pelanggan. Kemudian dengan menjelaskan cara pemakaian saat digunakan misalnya waktu yang tepat untuk pemakaiannya.

Pada penelitian ini, paling tinggi peranan dalam membentuk customer satisfaction pada functional benefits terletak di indikator dalam kehandalan merek The Body Shop saat digunakan. Peranan yang paling rendah membentuk customer satisfaction dari indikator functional benefits yaitu menunjukkan hasil sesuai dengan kegunaannya, ini berarti hasil dari kegunaan produk The Body Shop masih perlu ditingkatkan dengan cara memberikan tutorial kepada pelanggan untuk menggunakan produk yang dipilihnya, misalnya menyediakan individu untuk memberikan cara mengaplikasikan produk ke tubuh, sehingga pelanggan lebih mengerti fungsi serta hasil dari produk yang dipilinnya.

2. Symbolic benefits disini mengacu pada manfaat simbol diri yang dirasakan dari menggunakan produk merek The Body Shop. Symbolic benefits yang dirasakan pelanggan sesuai ataupun melebihi harapan pelanggan agar pelanggan puas akan produk dari merek The Body Shop. Symbolic benefits yang diberikan merek The Body Shop tentunya harus dipertahankan serta ditingkatkan agar hasil yang diterima pelanggan merek The Body Shop tetap memberikan simbol diri yang dirasakan secara maksimal.

Saat ini merek The Body Shop telah berhasil mencerminkan diri sebagai produk kosmetik berbahan dasar alami dan mengusung kampanye against animal testing, hal tersebut semakin memengahuri simbol diri yang diterima pelanggan saat menggunakan produknya.

Untuk mempertahankan symbolic benefits yang dirasakan pelanggan yaitu dengan cara tetap konsisten dalam menggunakan bahan baku alami untuk setiap produknya dan tetap mengusung kampanye against animal testing yang selama ini tertanam di benak pelanggan. Kemudian untuk meningkatkan symbolic benefits dapat dilihat dari indikator symbolic benefits yang membetuk customer satisfaction yakni membuat agar pelanggan dianggap oleh orang lain meningkat misalnya dengan merek The Body Shop menggunakan brand ambassador yang tepat untuk terlihat cantik alami.

Menurut peneliti mengikutsertakan pelanggan The Body Shop yang memiliki "LYB Member" dalam kegiatan yang mencerminkan ramah lingkungan misalnya "LYB Member" apabila telah melakukan pembelian diatas Rp.10.000.000,00 akan mendapatkan kesempatan menikmati kemudahan fasilitas untuk mengakses ke tempat wisata alam yang melindungi binatang yang biasa dijadikan uji coba dengan jalur 
khusus/VIP pelanggan The Body Shop. Sehingga dapat meningkatkan kepuasan pelanggan merek The Body Shop.

3. Experiential benefits adalah tingkat manfaat pengalaman yang dirasakan setelah menggunakan produk merek The Body Shop. Experiential benefits yang dirasakan pelanggan apakah kesenangan menggunakan produk merek The Body Shop sesuai ataupun melebihi ekspektasi pelanggan. Pada penelitian ini, experiential benefits merupakan hal yang paling tinggi yang dirasakan konsumen untuk menjadikan pelanggan puas terhadap merek The Body Shop. Ketika pelanggan merasa senang menggunakan produk merek The Body Shop, maka kepuasan pelanggan akan merek The Body Shop semakin tinggi. Sehingga alangkah baiknya menjaga agar experiential benefits tetap memberikan hasil yang maksimal kepada pelanggan.

Perlunya mempertahankan experiential benefits dalam pembentuk kepuasan pelanggan dengan cara mempertahankan pelayanan dalam memberikan informasi produk oleh karyawan. Terbuat dari bahan alami menjadikan pelanggan merek The Body Shop nyaman menggunakan produknya yang merupakan indikator dari experiential benefits pembentuk customer satisfaction.

Meningkatkan experiential benefits pada merek The Body Shop apabila mengacu pada indikator yang ada di experiential benefits pembentuk customer satisfaction maka harus meningkatkan frekuensi penggunaan terhadap produk The Body Shop. Sehingga menurut peneliti agar memberikan ekstra poin misalnya saat tidak ada ekstra poin syarat mendapatkan satu poin setiap melakukan pembelian nominal Rp25.000,00 sedangkan jika membeli produk dalam jangka waktu kurang atau sama dengan satu bulan maka poin yang didapatkan menjadi dua kali lipatnya. Jadi pelanggan The Body Shop tertarik untuk membeli produk yang sama dalam jangka waktu dekat yang mengharuskan pelanggan lebih meningkatkan intensitas pemakaian produk merek The Body Shop.

Menambahkan adanya booth make over, sehingga selain dapat membeli produk yang diinginkan juga dapat sekaligus merasakan kesengangan dari mendapatkan free make over bagi pelanggan yang telah melakukan transaksi sebesar nominal yang disepakati pihak manajemen atau menggunakan poin yang telah dikumpulkan dari kartu member yang dimiliki pelanggan.

\section{KESIMPULAN DAN SARAN}

\subsection{Kesimpulan}

Penelitian ini dilakukan untuk menguji peran functional benefits, symbolic benefits, experiential benefits dan customer satisfaction sebagai pembentuk loyalty intention pada customer The Body Shop. Hasil analisis data yang dilakukan dengan menggunakan analisis SEM menunjukkan bahwa seluruh hipotesis memiliki pengaruh positif dan signifikan. Dengan menggunakan studi penelitian functional benefits, symbolic benefits dan experiential benefits berpengaruh positif terhadap customer satisfaction dan customer satisfaction berpengaruh positif terhadap loyalty intention. 
Analisis Peran ...

\subsection{Saran}

Hasil dari penelitian ini telah menunjukkan adanya pengaruh yang positif dan signifikan pada setiap hipotesisnya. Tentunya, penelitian ini masih memiliki kekurangan sehingga masih memerlukan penyempurnaan untuk penelitian di masa yang akan datang. Oleh karena itu, beberapa saran yang mungkin dapat diberikan untuk perusahaan dan untuk penelitian selanjutnya.

1. Sebagai pihak yang menyediakan jasa kepada pelanggannya maka The Body Shop harus mempertahankan dan lebih meningkatkan functional benefits agar pelanggan yang menggunakan ataupun ingin membeli produk dari merek The Body Shop mempunyai rasa antusias jika produk merek The Body Shop memiliki fungsi yang sesuai dengan kegunaan produk jika mendengar merek The Body Shop pada masa yang akan datang.

2. Symbolic benefits dalam objek penelitian ini yaitu merek The Body Shop bisa melakukan inovasi yaitu menggunakan brand ambassador dan sering mengikutsertakan pelanggan The Body Shop yang memiliki "LYB" Member mendapatkan kesempatan menikmati kemudahan fasilitas untuk mengakses ke tempat wisata alam yang melindungi binatang yang biasa dijadikan uji coba. Dengan demikian, simbol diri dapat meningkat kemudian mempengaruhi kepuasan pelanggan yang akhirnya meningkatkan loyalty intention.

3. Experiential benefits dalam konteks ini The Body Shop bisa menambahkan adanya ekstra poin, booth make over, free make over bagi pelanggan yang telah melakukan transaksi sebesar nominal yang disepakati pihak manajemen atau menggunakan poin yang telah dikumpulkan dari kartu member yang dimiliki pelanggan.

4. Bagi peneliti selanjutnya diharapkan mengganti objek yang diteliti dengan objek yang berbeda, dengan contoh fashion, telekomunikasi, makanan atau minuman. Objek penelitian tersebut pasti memiliki proses keinginan untuk loyal yang harus dianalisa lebih lanjut untuk peneliti lainnya. Aspek yang mempengaruhi loyalty intention pada industri tersebut juga bisa diperluas. Contohnya variabel yaitu brand attributes, brand trust, commitment. Nantinya diharapkan penelitian mengenai loyalty intention akan mengukur dan menganalisa segala aspek yang berhubungan dan terkait sehingga dapat menghasilkan penelitian yang lebih kaya dan bermanfaat.

\section{DAFTAR PUSTAKA}

Anderson, R. E., \& Srinivasan, S. S. (2003). E-satisfaction and e-loyalty: A contingency framework. Psychology and Marketing, 20(2), 123-138.

Baharun, R., Hashim, N. H., \& Sulong, N. Z. (2013). Benefit Segmentation for Unit trust Products in Malaysian Financial service Industry. Jurnal Kemanusiaan.

Bearden, W., \& Teel, J. (1983). Selected determinants of consumer satisfaction and complaint reports. Journal of Marketing Research, 20(1), 21-28.

Bei, L., \& Chiao, Y. (2001). An integrated model for the effects of perceived product, perceived service quality, and perceived price fairness on consumer satisfaction and loyalty. Journal of Consumer Satisfaction, Dissatisfaction and Complaining Behavior Dissatisfaction, 14, 125-140. 
Bitner, M. J., Faranda, W. T., Hubbert, A. R., \& Zeithaml, V. A. (1997). Customer contributions and roles in service delivery. International Journal of Service Industry Management.

Bloemer, J., \& Ruyter, K. de. (1998). On the relationship between store image, store satisfaction. European Journal of Marketing, 32(5), 499-513.

Cadotte, E. R., Woodruff, R. B., \& Jenkins, R. L. (1987). Expectations and norms in models of consumer satisfaction. Journal of Marketing Research, 24(3), 305-314.

Chen, C.-F., \& Chen, C.-T. (2014). The Effect of Higher Education Brand Images on Satisfaction and Lifetime Value from Students' Viewpoint. Anthropologist, 17(1), 137145.

Chiou, J.-S., Droge, C., \& Hanvanich, S. (2002). Does Customer Knowledge Affect How Loyalty is Formed? Journal of Service Research, 5(2), 113-124.

Churcill Jr, G. A., \& Surprenant, C. (1982). An investigation into the determinants of customer satisfaction. Journal of Marketing Research, 19(4), 491-504.

Day, G. (1969). A two-dimensional concept of brand loyalty. Journal of Advertising Research, 9(3), 29-35.

Efridha, I. (2014). Review: The Body Shop Tea Tree Oil \& Tea Tree Skin Clearing Toner. Retrieved from http://inggitoktaryan.blogspot.com/2014/03/review-body-shop-tea-treeoil-tea-tree.html

Fornell, C., Johnson, M., \& Anderson, E. (1996). The American customer satisfaction index: nature, purpose, and findings. The Journal of ..., 60(October), 7-18.

Hero, C. (2015). Presentation MP. Retrieved from https://www.coursehero.com/file/11672870/Presentation-MP/

Hsieh, M.-H., Pan, S., \& Setiono, R. (2004). Product-, corporate-, and country-image dimensions and purchase behavior: A multicountry analysis. Journal of the Academy of Marketing Science, 32(3), 251-270.

Jessica, V. (2011). Tinjauan Lapangan The Body Shop. Retrieved from https://vionajessica.wordpress.com/2011/06/06/bab-iii-tinjauan-lapangan-the-bodyshop/

Johnson, M. D., Herrmann, A., \& Huber, F. (2006). The Evolution of Loyalty Intentions. Journal of Marketing, 70(2), 122-132.

Jones, T. O., \& Sasser, J. W. E. (1995). Why satisfied customers defect. Harvard Business Review, 73(6), 88-99.

Kandampully, J., \& Suhartanto, D. (2000). Customer loyalty in the hotel industry: The role of customer satisfaction and image. International Journal of Contemporary Hospitality Management, 12(6), 346-351.

Keller, K. L. (1993). Conceptualizing, Measuring, and Managing Customer-Based Equity. Journal of Marketing, 57(1), 1-22.

Keller, K. L. (2013). Strategic Brand Management: Building, Measuring, and Managing Brand Equity (Fourth Edi.). Pearson Education Limited.

Koo, D. (2003). Inter-relationships among store images, store satisfaction, and store loyalty among Korea discount retail patrons. Asia Pacific Journal of Marketing and Logistics, 15(4), 42-71. 
Analisis Peran ...

Lau, G., \& Lee, S. (1999). Consumers' trust in a brand and the link to brand loyalty. Journal of Market Focused Management, 4, 341-370.

Malhotra, N. K. (2010). Marketing Research: An Applied Approach. United States of America: Pearson Prentice Hall.

Mulyadi, A. (2015). PNM SInergi Sesama BUMN untuk Genjot Promosi. Retrieved May 27, 2015, from http://www.indopos.co.id/2015/05/pnm-sinergi-sesama-bumn-untukgenjot-promosi.html

Nam, J., Ekinci, Y., \& Whyatt, G. (2011). Brand equity, brand loyalty and consumer satisfaction. Annals of Tourism Research, 38(3), 1009-1030.

Neupane, R. (2015). The Effects of Brand Image on Customer Satisfaction and Loyalty Intention in Retail Super Market Chain UK. International Journal of Social Sciences and Management, 2(1), 9-26.

Oliver, R. L. (1980). A cognitive model of the antecedents and consequences of satisfaction decisions. Journal of Marketing Research, 17(4), 460-469.

Oliver, R. L., \& DeSarbo, W. S. (1988). Response determinants in satisfaction judgments. Journal of Consumer Research, 14(4), 495-507.

Oliver, R. L., \& Swan, J. E. (1989). Equity and disconfirmation perceptions as influences on merchant and product satisfaction. Journal of Consumer Research, 16(3), 372-383.

Olson, J. C., \& Dover, P. A. (1979). Disconfirmation of consumer expectations through product trial. Journal of Applied Psychology, 64(2), 179-189.

Pullman, M. E., \& Gross, M. A. (2004). Ability of experience design elements to elicit emotions and loyalty behaviors. Decision Sciences, 35(3), 551-578.

Purnomo, H. (2014). Negara dengan Penduduk Terbanyak di Dunia, RI Masuk 4 Besar. Retrieved from http://finance.detik.com/read/2014/03/06/134053/2517461/4/negaradengan-penduduk-terbanyak-di-dunia-ri-masuk-4-besar

Reynolds, K. E., \& Beatty, S. E. (1999). Customer benefits and company consequences of customer-salesperson relationships in retailing. Journal of Retailing, 75(1), 11-32.

Reynolds, T. J., \& Gutman, J. (1984). Advertising is image management. Journal of Advertising Research, 24(1), 27-37.

Reynolds, W. H. (1965). The role of the consumer in image building. California Management Review, 7(3), 69-76.

Russell-Bennett, R., \& Rundle-Thiele, S. (2004). Customer Satisfaction Should Not Be The Only Goal. Journal of Services Marketing, 18(7), 514-523.

Sivadas, E., \& Baker-Prewitt, J. L. (2000). An examination of the relationship between service quality, customer satisfaction, and store loyalty. International Journal of Retail and Distribution Management, 28(2), 73-82.

Sondoh Jr., S. L., Omar, M. W., Wahid, N. A., Ismail, I., \& Amran, H. (2007). The Effect of Brand Image On Overall Satisfaction And Loyalty Intention In The Context of Color Cosmetic. Asian Academy of Management, 12(1), 83-107.

Spreng, R. A., \& Olshavsky, R. W. (1993). A desires congruency model of consumer satisfaction. Journal of the Academy of Marketing Science, 21(3), 169-177.

Sweeney, J. C., \& Soutar, G. N. (2001). Consumer perceived value: The development of a multiple itenl scale. Journal of Retailing, 77(2), 203-220. 
Szymanski, D. M., \& Henard, D. H. (2001). Customer satisfaction: A meta-analysis of the empirical evidence. Journal of the Academy of Marketing Science, 29(1), 16-35.

The Body Shop. (2015). TAMPIL CANTIK ALAMI DENGAN RANGKAIAN PRODUK YANG KAMI TAWARKAN BERASAL DARI ALAM! Retrieved from http://www.thebodyshop.co.id/

Tse, D., \& Wilton, P. (1988). Models of consumer satisfaction formation: an extension. Journal of Marketing Research, 25(2), 204-212.

Veloutsou, C., Gilbert, G. R., Moutinho, L., \& Goode, M. M. H. (2005). Measuring transaction-specific satisfaction in services Are the measures transferable across cultures? European Journal of Marketing, 39(5/6), 606-628.

Wang, W.-H., Liang, C.-J., \& Joonas, K. (2009). Customer Relationship Investments, Value to the Customer, and Value to the Firm: Integrating Attributes and Benefits. Southwest Business and Economics Journal, 23-46.

Wang, Y., Tang, T.-I., \& Tang, J. E. (2001). An Instrument for Measuring Customer Satisfaction Toward Web Sites That Market Digital Products and Services. Journal of Electronic Commerce Research, 2(3), 89-102.

Woodruff, R. B., Cadotte, E. R., \& Jenkins, R. L. (1983). Modeling consumer satisfaction processes using experience-based norms. Journal of Marketing Research, 20(3), 296304.

Yang, Z., \& Peterson, R. T. (2004). Customer perceived value, satisfaction, and loyalty: The role of switching costs. Psychology and Marketing, 21(10), 799-822. 